\title{
Selective Attention and Internal Constraints: There Is More to the Flanker Effect Than Biased Contingencies
}

\author{
J. Toby Mordkoff
}

$I^{\prime}$ $\mathrm{n}$ both natural and laboratory settings, people are often required to focus their attention on a single stimulus or spatial location and ignore everything else that is simultaneously in view. The experimental evidence suggests, however, that when attempting to focus their attention, people can seldom completely succeed. For example, when subjects are asked to view three-item displays, restricting their attention to the center stimulus (hereafter, the target), the identity of the task-irrelevant left and right stimuli (the flankers) have consistent effects on performance. In particular, if subjects are required to press the left response key when the target letter is an $A$ and the right key when the target is a $Z$, then left-key responses are faster (and more accurate) to displays of $A A A$ than to $Z A Z$ (e.g., B. A. Eriksen \& Eriksen, 1974). Similarly, under this particular target-toresponse mapping, right-key responses are faster to $Z Z Z$ than to $A Z A$. In summary, selective-attention tasks of this sort have shown that performance depends not only on the task-relevant target, but also on the task-

This research was supported by Grant T32-MH14268 from the National Institute of Mental Health to the University of California, San Diego. I thank Charles W. Eriksen, Juan Botella, Art Kramer, Jeff Miller, and Cathleen Moore for their advice and comments and Dana Feinberg, Rima Kliore, and Danielle Picher for their help in conducting the experiments. 
irrelevant flankers. This pattern of results, which demonstrates a failure of selective attention, is typically referred to as the flanker effect, and much of what is known about this phenomenon may be directly traced to the work of Charles W. Eriksen (e.g., B. A. Eriksen \& Eriksen, 1974; see C. W. Eriksen \& Schultz, 1979, for a review).

The flanker effect has not only been of interest in and of itself, but has also been used as a tool in studies of other attentional mechanisms. By manipulating the separation between the flankers and the center (target) letter, for example, investigators have used the flanker effect as a measure of the size of the attentional spotlight (e.g., C. W. Eriksen \& Hoffman, 1972, 1973; C. W. Eriksen \& St. James, 1986; C. W. Eriksen \& Yeh, 1985). More recently, the flankers task has been used in a series of studies examining the psychophyisiological correlates of selective attention (e.g., Coles, Gratton, Bashore, Eriksen, \& Donchin, 1985; Gratton, Coles, Sirevaag, Eriksen, \& Donchin, 1988).

A more basic question, however, concerns why the task-irrelevant flankers-when they actually are processed-have any effect on performance. In other words, that the flankers are identified does not explain why their identities have an effect on response time. After all, subjects are instructed to ignore the flankers, and the identity of the flankers is usually uncorrelated with the identity of the target and correct response, so why do the flankers produce the effects that they do?

Previous answers to this question have usually invoked the concepts of response priming and response competition. C. W. Eriksen and Schultz (1979), for example, have argued that

information about stimuli accumulates gradually in the visual system, and as it accumulates, responses are concurrently primed or partially activated. We conceive of several processes or levels comprising the events from stimulation to response activation. With the onset of stimulation, input channels begin to feed a continuous output to feature detectors which, in turn, continuously feed to form units. The output from the form units is a priming or activation flow to the response system. The output from each process becomes increasingly more detailed or exact over time as energy is integrated in the visual sense organ. The effect at the response level, with this continuous flow, is an initial priming of a wide range of responses. 
But as the processing at the lower levels proceeds in time, the priming flow becomes increasingly restricted to fewer and fewer responses, namely, those that are still viable alternatives in terms of the increasingly more exact or complete output of the lower processes. (p. 252)

An implicit argument within C. W. Eriksen and Schultz's explanation of the flanker effect is that once a flanking letter has been fully identifiedincluding recognition that the letter is in a task-irrelevant position-it will not be allowed further access to response processes. On this assumption it makes sense to argue in favor of continuous processing, because if no output to response processes were to be made available until all perceptual processing had finished, then there would be no reason for the flankers to have any effect.

However, this view makes an assumption that might not be warranted. In particular, this analysis appears to assume that once fully processed by perceptual mechanisms, information concerning the letters in taskirrelevant locations is represented in a way that makes its exclusion from response processes possible. This may not be correct. Furthermore, on an alternative view, the effects of the identity of task-irrelevant letters may be seen not as a failure of selective attention, but as a success by mechanisms responsible for extracting and using other forms of information that may be present within an experimental design.

\section{INTERNAL CONSTRAINTS}

In some recent analyses of the human ability to divide visual attention (Mordkoff \& Egeth, 1994; Mordkoff \& Yantis, 1991), the discussion highlighted how performance can be affected by certain subtle contingencies, also known as internal constraints (see Garner, 1962). This work has shown, for example, that when the presence of a specific letter in one display location is correlated with the presence of a target in another location, this correlation can significantly affect response time. In particular, if the correlation is positive, then responses are made faster; if the correlation is negative, responses are slowed. These contingencies had been left as uncontrolled variables in previous work concerning divided attention; however, only a model that was sensitive to these contingencies was found to 
provide a complete account of the data (see Mordkoff \& Yantis, 1991, for a review of contingency analysis; see Garner, 1962, for a complete introduction to internal constraints). One issue to be examined regarding failures of selective attention, therefore, concerns the possibility that contingencies have been present in the designs of these experiments as well.

\section{Definition of Terms}

In this section, before continuing with a discussion of the experiments, I introduce the nomenclature, starting with the labels for the various conditions in flankers-task experiments. Throughout this chapter, it is assumed that all letters from the start of the alphabet are targets assigned to the left-hand response. Letters from the end of the alphabet are right-hand targets, and letters from the middle are neutral and assigned to neither response.

Trials on which the flankers are identical to the target (e.g., $A A A$ ) or are letters assigned to the same response as the target (e.g., $B A B$ ) are compatible. Trials with flankers that are assigned to the opposite response from the target (e.g., ZAZ) are incompatible. The flanker effect is defined as the difference in mean reaction time (RT) between compatible and incompatible trials. Finally, trials with flankers that are assigned to neither response (e.g., NAN) are neutral.

Next, for the equations describing the various contingencies, superscripts always specify spatial location. For example, $A^{\mathrm{C}}$ denotes the letter $A$ in the center (target) location, whereas $Z^{\mathrm{F}}$ indicates that the flankers are $Z$ s. Thus, the display $Z A Z$ is completely described by $A^{\mathrm{C}} \& Z^{\mathrm{F}}$. A superscript @ (an at sign) denotes the presence of at least one exemplar of a given stimulus anywhere within a display; for example, $A^{@} \& Z^{@}$ partially describes both $A Z A$ and $Z A Z$, because both displays include at least one $A$ and at least one $Z$.

In contrast, subscripts always denote the correct response. Thus, $\mathrm{R}_{\mathrm{L}}$ indicates that a left-key response is correct, and $\mathrm{R}_{\mathrm{R}}$ indicates that a rightkey response is correct. $\mathrm{R}_{\mathrm{L}}$ partially describes both $A A A$ and $Z A Z$.

To be explicit about the relevant contingencies, the following discussion refers to the experimental design shown in Table 1. This design is typical of flankers-task experiments that include only compatible and incompatible trials. The first set of contingencies to be examined are those referred to as interstimulus contingencies (Mordkoff \& Yantis, 1991). These contingencies involve correlations between specific letters in specific lo- 


\section{Table 1}

Trials per Block by Display Type for the Low-Correlation Condition in Experiment 1

\begin{tabular}{lllllll}
\hline \multirow{2}{*}{\begin{tabular}{l} 
Target \\
\cline { 5 - 6 } letter
\end{tabular}} & Correct & & \multicolumn{5}{c}{ Flanking letters } \\
\hline$A$ & response & $A$ & $Z$ & $B$ & $Y$ & $N$ \\
$Z$ & $\mathrm{R}_{\mathrm{L}}$ & 5 & 5 & 0 & 0 & 0 \\
& $\mathrm{R}_{\mathrm{R}}$ & 5 & 5 & 0 & 0 & 0 \\
\hline
\end{tabular}

NOTE: $\mathrm{R}_{\mathrm{L}}=$ left-key response; $\mathrm{R}_{\mathrm{R}}=$ right-key response.

cations, regardless of response relevance. In the case of the design shown in Table 1, the identity of the flanking letters gives no information about the identity of the target letter because

$$
P\left(A^{\mathrm{C}} \mid A^{\mathrm{F}}\right)=P\left(Z^{\mathrm{C}} \mid A^{\mathrm{F}}\right)
$$

and

$$
P\left(Z^{\mathrm{C}} \mid Z^{\mathrm{F}}\right)=P\left(A^{\mathrm{C}} \mid Z^{\mathrm{F}}\right)
$$

where $P\left(A^{\mathrm{C}} \mid A^{\mathrm{F}}\right)$, for example, is the probability of an $A$ appearing in the center location given that the flanking letters are also As. ${ }^{1}$ Whenever equalities analogous to Equations 1a and $1 \mathrm{~b}$ are upheld, the design can be said to include no flanker-target interstimulus contingencies. Except for a few exceptions (Logan \& Zbrodoff, 1979; Miller, 1987; Paquet \& Lortie, 1990), experiments concerning selective attention have not included any flanker-target interstimulus contingencies.

Furthermore, because the identity of the target letter determines which response is correct, there is no response information carried by the flankers, either, because

$$
P\left(\mathrm{R}_{\mathrm{L}} \mid A^{\mathrm{F}}\right)=P\left(\mathrm{R}_{\mathrm{R}} \mid A^{\mathrm{F}}\right),
$$

${ }^{1}$ It is important to note that Equations $1 \mathrm{a}$ and $1 \mathrm{~b}$ assume that the two target letters appear equally often in the center location; that is, $P\left(A^{\mathrm{C}}\right)=P\left(Z^{\mathrm{C}}\right)$. Under more complicated designs, one must compare each conditional probability with the appropriate baseline. Thus, for example, the complete equations to verify that no flanker-target interstimulus contingencies exist within the design shown in Table 1 are $P\left(A^{\mathrm{C}}\right.$ $\left.A^{\mathrm{F}}\right)=P\left(A^{\mathrm{C}} \mid Z^{\mathrm{F}}\right)=P\left(A^{\mathrm{C}}\right)$ and $P\left(Z^{\mathrm{C}} \mid A^{\mathrm{F}}\right)=P\left(Z^{\mathrm{C}} \mid Z^{\mathrm{F}}\right)=P\left(Z^{\mathrm{C}}\right)$. 
and

$$
P\left(\mathrm{R}_{\mathrm{R}} \mid Z^{\mathrm{F}}\right)=P\left(\mathrm{R}_{\mathrm{L}} \mid Z^{\mathrm{F}}\right)
$$

where $P\left(\mathrm{R}_{\mathrm{L}} \mid A^{\mathrm{F}}\right)$, for example, is the probability that a left-key response is correct given that the flanking letters are $A s .{ }^{2}$ Thus, we can say that the design shown in Table 1 includes no flanker-response contingencies, either (cf. nontarget-response contingencies, Mordkoff \& Yantis, 1991). That these values are also equal is not unusual. In summary, then, the source of the flanker effect is clearly not in the operation of mechanisms sensitive to either interstimulus or flanker-response contingencies, at least in the way that these contingencies have been defined.

\section{A NEW TYPE OF CONTINGENCY}

To this point I have considered only contingencies that rely on locationspecific conditional probabilities. In other words, all of the conditional probabilities reviewed above have concerned letters in specific locations as the potential sources of useful information. This may not be sufficient. There may be other contingency-sensitive mechanisms that rely on different forms of information. For example, Miller (1987) has argued that

in the paradigm used by C. W. Eriksen and his associates (e.g., Eriksen \& Schultz, 1979), the presence of a particular letter in the display, ignoring location, has been a valid cue as to the correct response. Although the response was independent of the identity of the letter in the flanking positions, the presence of a certain target identity anywhere in the display was still correlated with the response, because of the many trials on which that target appeared in the relevant center position. Overall, when that particular target letter was present somewhere in the display, the response associated with that target was correct more often than not. Perhaps, then, a target cues a response not only because it is a target, but also because the presence of its identity is correlated with that response. (p. 431)

\footnotetext{
${ }^{2}$ Equations $2 \mathrm{a}$ and $2 \mathrm{~b}$ have also been simplified by the assumption that $P\left(\mathrm{R}_{\mathrm{L}}\right)=P\left(\mathrm{R}_{\mathrm{R}}\right)$.
} 
In effect, Miller has argued that there may be a new form of contingency operating under selective-attention tasks-one that does not rely on location-specific information, but only on the presence of certain letters anywhere within a display. Because the psychological device that represents a letter regardless of location has previously been called a typenode (e.g., Kanwisher, 1987, 1991; Mozer, 1989; cf. logogen, Morton, 1969; feature map, Treisman, 1988), these correlations are termed here typenoderesponse contingencies.

The two panels of Figure 1 illustrate how this sort of representational device operates. The upper panel depicts the state of the system when it has been presented with three As in a row, as on a compatible flankerstask trial. Each letter is represented by a link between a typenode and a location token. Because at least one $A$ is being represented, the $A$ typenode is active. In contrast, the $Z$ typenode is inactive, because no $Z$ s have been presented.

The lower panel shows how the stimuli on an incompatible trial (including both an $A$ and some $Z s$ ) would be represented. In this case, both typenodes are active. To be clear: A typenode is assumed to become active whenever the stimulus for which it codes has been perceived from any location within the visual display. For present purposes it is also assumed that all typenodes must be in one of two states, active or inactive, and that the number of exemplars (more than one) of the represented stimulus has no effect on typenode activity.

\section{Typenode-Response Contingency Bias}

Using the terminology introduced earlier, with a superscript @ denoting the presence of a letter anywhere within a display, the typenode-response contingency (TRC) between the letter $A$ and response $\mathrm{R}_{\mathrm{L}}$ can be defined as follows:

$$
\operatorname{TRC}\left(A \rightarrow \mathrm{R}_{\mathrm{L}}\right)=P\left(\mathrm{R}_{\mathrm{L}} \mid A^{@}\right) .
$$

For the design shown in Table 1 , the value of $\operatorname{TRC}\left(A \rightarrow \mathrm{R}_{\mathrm{L}}\right)$ is 0.67 , because 10 of the 15 trials that contain at least one $A$ in the display require a left-key response. Similarly, the value of $\operatorname{TRC}\left(Z \rightarrow \mathrm{R}_{\mathrm{R}}\right)$ is also 0.67 , because the design is symmetrical. In contrast, the values of $\operatorname{TRC}\left(A \rightarrow \mathrm{R}_{\mathrm{R}}\right)$ and $\operatorname{TRC}\left(Z \rightarrow \mathrm{R}_{\mathrm{L}}\right)$ are both 0.33 (5 out of 15 each). 
Type-node Representation of AAA

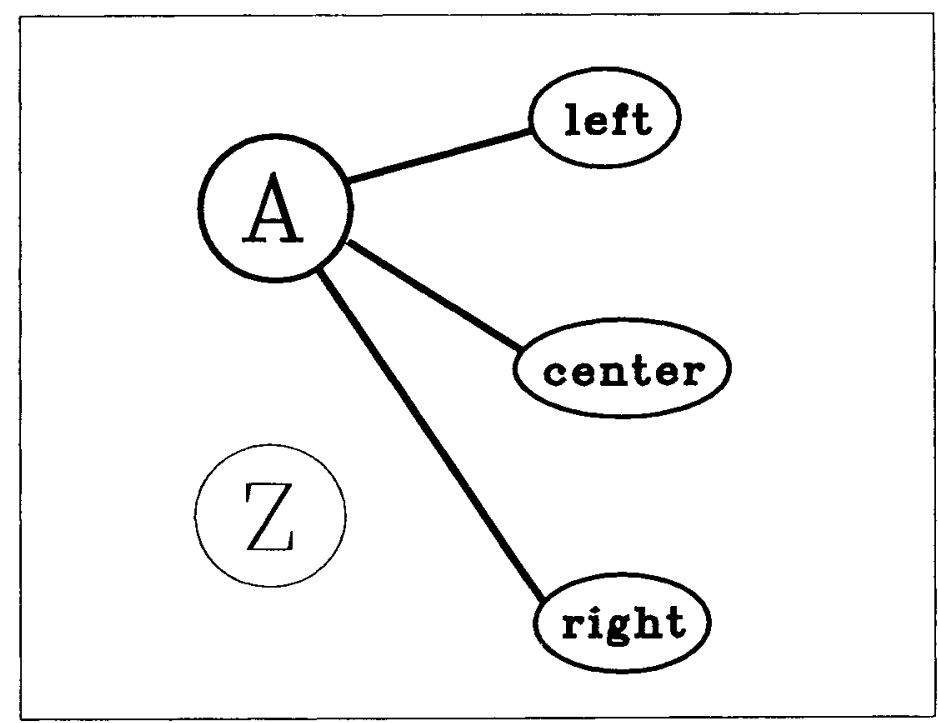

Type-node Representation of ZAZ

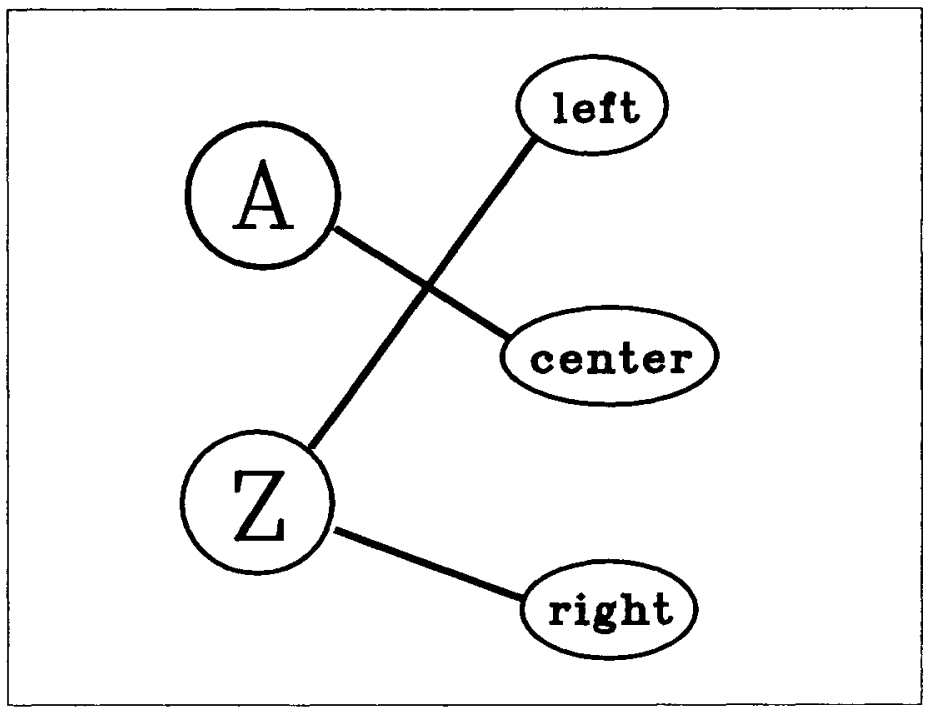

\section{Figure 1}

Schematic of part of a typenode network of visual short-term memory. The upper panel shows the network when representing a row of three As. Note that the $Z$ typenode is inactive (thin circle). The lower panel shows the network representing the stimulus string $Z A Z$. In this case, both typenodes are active (thick circles). 
The potential effect on performance that could result from the use of contingency information based on typenode activity-here labeled typenode-response contingency bias (TRCB)—is found by subtracting the baseline probability of a given response from the conditional. For example,

$$
\begin{aligned}
\operatorname{TRCB}\left(A \rightarrow \mathrm{R}_{\mathrm{L}}\right) & =\operatorname{TRC}\left(A \rightarrow \mathrm{R}_{\mathrm{L}}\right)-P\left(\mathrm{R}_{\mathrm{L}}\right) \\
& =P\left(\mathrm{R}_{\mathrm{L}} \mid A^{@}\right)-P\left(\mathrm{R}_{\mathrm{L}}\right) .
\end{aligned}
$$

For the design shown in Table 1, the values of TRCB are +0.17 for both $A \rightarrow \mathrm{R}_{\mathrm{L}}$ and $Z \rightarrow \mathrm{R}_{\mathrm{R}}$. The value is -0.17 for both $A \rightarrow \mathrm{R}_{\mathrm{R}}$ and $Z \rightarrow \mathrm{R}_{\mathrm{L}}$.

This brings us to a possible source of the flanker effect. Note first that compatible displays that require $\mathrm{R}_{\mathrm{L}}$ contain only $A$ s, whereas incompatible displays that require $\mathrm{R}_{\mathrm{L}}$ contain both at least one $A$ and at least one $Z$. Thus, given that the correct response is $\mathrm{R}_{\mathrm{L}}$ (i.e., the target is an $A$ ), there is an extra set of contingencies operating on incompatible trials as compared with compatible trials. In particular, although both types of trial will enjoy the +0.17 contingency between the typenode for $A$ and $\mathrm{R}_{\mathrm{L}}$ (which would speed responding), the incompatible trials will also have the -0.17 contingency between the typenode for $Z$ and $R_{\mathrm{L}}$ (which would slow responding). In summary, then, the value of TRCB for incompatible letter-response pairs gives a measure of the typenode-response contingency bias against incompatible trials; in this case, TRCB is 0.17 . Because all experiments using this sort of flankers-task design have included such a bias against incompatible trials, the possibility that typenode-response contingencies are responsible for the observed flanker effect is viable.

\section{Manipulating TRCB}

In order to test this contingency-based explanation of the flanker effect, a method of manipulating TRCB is required. Fortunately, a straightforward technique is available; it involves the use of neutral trials; that is, those trials on which the flankers are letters not assigned to either response. Consider the experimental design shown in Table 2. In this case, many trials involve the neutral flanker $N$. By Equation 3, the value of TRC $\left(B \rightarrow R_{L}\right)$ is +0.83 , because 10 of the 12 displays that include at least one $B$ require a left-key response. Similarly, the value of $\operatorname{TRC}\left(Y \rightarrow R_{L}\right)$ is -0.83 . Thus, 
under the design shown in Table 2, TRCB is 0.33 , which is twice the value obtained using the design shown in Table 1. In general, increasing the proportion of neutral trials within a given design will increase the value of TRCB. More specifically, increasing the proportion of trials on which a given target is surrounded by neutral flankers will increase the contingency between that letter and its associated response.

\section{EXPERIMENT 1}

The first experiment was conducted as an initial test of a contingencybased explanation of the flanker effect. This was done by combining the designs shown in Tables 1 and 2. Two letters were assigned to each response; one for the design shown in Table 1 and another for the design shown in Table 2 . There was only one neutral (flanker) letter, because only the second design includes any neutral trials. In general, Experiment 1 included a within-subjects, within-blocks manipulation of TRCB. Note, however, that the letters included in the trials with nonzero frequencies in Table 1 do not appear in the trials in Table 2. This allowed for separate calculations of TRCB for the two main conditions.

\section{Method}

\section{Subjects}

Twenty-four undergraduates from the University of California, San Diego, participated for partial course credit. All reported normal or corrected-tonormal visual acuity. Each subject participated in an individual 50-min session.

\section{Tab le 2}

Trials per Block by Display Type for the High-Correlation Condition in Experiment 1

\begin{tabular}{|c|c|c|c|c|c|c|}
\hline \multirow{2}{*}{$\begin{array}{l}\text { Target } \\
\text { letter }\end{array}$} & \multirow{2}{*}{$\begin{array}{l}\text { Correct } \\
\text { response }\end{array}$} & \multicolumn{5}{|c|}{ Flanking letters } \\
\hline & & A & $Z$ & $B$ & $Y$ & $N$ \\
\hline$B$ & $\mathrm{R}_{\mathrm{L}}$ & 0 & 0 & 2 & 2 & 6 \\
\hline$Y$ & $\mathrm{R}_{\mathrm{R}}$ & 0 & 0 & 2 & 2 & 6 \\
\hline
\end{tabular}

NOTE: $\mathrm{R}_{\mathrm{L}}=$ left-key response; $\mathrm{R}_{\mathrm{R}}=$ right-key response. 


\section{Apparatus, Experimental Design, and Stimuli}

The stimuli were presented on NEC Multisync monitors (Tokyo, Japan) controlled by IBM-compatible microcomputers using EGA cards. The subjects responded by pressing buttons on a custom-made response box using their left and right index fingers.

The experiment included two main conditions (within-subjects), as defined by two sets of targets. One condition involved a low-strength correlation between typenode activity and the correct response (i.e., a relatively low value of TRCB); this was achieved by never having the lowcorrelation targets surrounded by neutral flankers (see Table 1). The other condition involved a high-strength correlation; these targets were often surrounded by neutral flankers (see Table 2). As described above, the value of TRCB for the low-correlation condition was 0.17 . For the highcorrelation condition, it was $\mathbf{0 . 3 3}$.

Each subject was given a different mapping of the letters $A, O, T, V$, and $X$. Two of the letters were assigned to the left-button response (one as the low-correlation target, the other as the high-correlation target), two others were assigned to the right-button response, and the fifth letter was the neutral flanker and only appeared in the nontarget locations.

Each display contained three letters: the central target and two identical flankers to the left and the right. Each letter was $0.90 \mathrm{~cm}$ tall and 0.64 $\mathrm{cm}$ wide, and the centers of the flankers were $1.10 \mathrm{~cm}$ from fixation. From a viewing distance of $45 \mathrm{~cm}$, each letter subtended $1.15^{\circ} \times 0.82^{\circ}$ of visual angle, and the flanker locations were $1.40^{\circ}$ (center-to-center) from fixation. The fixation cross was $0.30 \mathrm{~cm} \times 0.30 \mathrm{~cm}\left(0.38^{\circ} \times 0.38^{\circ}\right)$.

\section{Procedure}

Each trial began with the presentation of the fixation cross for $1,000 \mathrm{~ms}$. After a 500-ms blank interval, the trial display appeared and remained visible until a response was made or $1,500 \mathrm{~ms}$ had elapsed. The intertrial interval was $1,000 \mathrm{~ms}$.

There were 13 blocks of trials in a session. The first block included only 20 trials and was labeled practice. After each trial in the practice block, subjects were given RT feedback if correct and were reminded of the letters-to-responses mapping if incorrect. The purpose of this block was to teach subjects their mapping. The data from this block were not recorded. 
The remaining 12 blocks were each approximately 50 trials long, depending on the number of errors made by the subject. The design calls for 40-trial blocks, but a randomly selected recovery trial followed each error. There were also five warm-up trials at the start of each block. The data from the warm-up and recovery trials were not included in any analysis. RTs less than $150 \mathrm{~ms}$ or more than $1,200 \mathrm{~ms}$ were also discarded.

After each block of trials, subjects were given mean-RT and accuracy feedback during an enforced 7 -s break. If their error rate was above $5 \%$, they were also told to be "more careful." Subjects were given a 5-min break after the sixth full block. The order of trials was randomized prior to each block.

\section{Data Analysis}

The magnitude of the flanker effects (i.e., mean incompatible RT less mean compatible RT) was analyzed in a $2 \times 3$ analysis of variance (ANOVA) with correlation strength and session part as within-subject factors. The data were analyzed in terms of the flanker effects, rather than mean RT, to avoid having to interpret a three-way interaction. (The flanker effect, itself, is the interaction between target identity and flanker identity.) The data were divided into three parts because previous experiments have suggested that contingencies require some time to learn. Session Part 1 included Blocks 1-4; Session Part 2, Blocks 5-8; and Session Part 3, Blocks 9-12. Planned comparisons were also conducted testing for an effect of correlation strength within each session part. A similar set of analyses concerned the flanker effect in mean error rates.

\section{Results}

The mean flanker effects from Experiment 1 are shown in Figure 2. There was no significant effect of session part on the overall flanker effect, $F(2$, $46)=1.98$, nor was the main effect of correlation strength reliable, $F(1$, $23)<1$. The interaction between these two variables was significant, $F(2$, 46) $=4.13, p<.025$. The planned comparisons showed that during Session Part 1 there was an unreliably larger flanker effect in the lowcorrelation condition, $t(23)=1.09$. During Part 2 there was an insignificantly larger flanker effect in the high-correlation condition, $t(23)=1.55$. However, during Part 3 there was a significant effect of correlation strength, with a larger flanker effect in the high-correlation condition, $t(23)=1.86, p<.05$. 


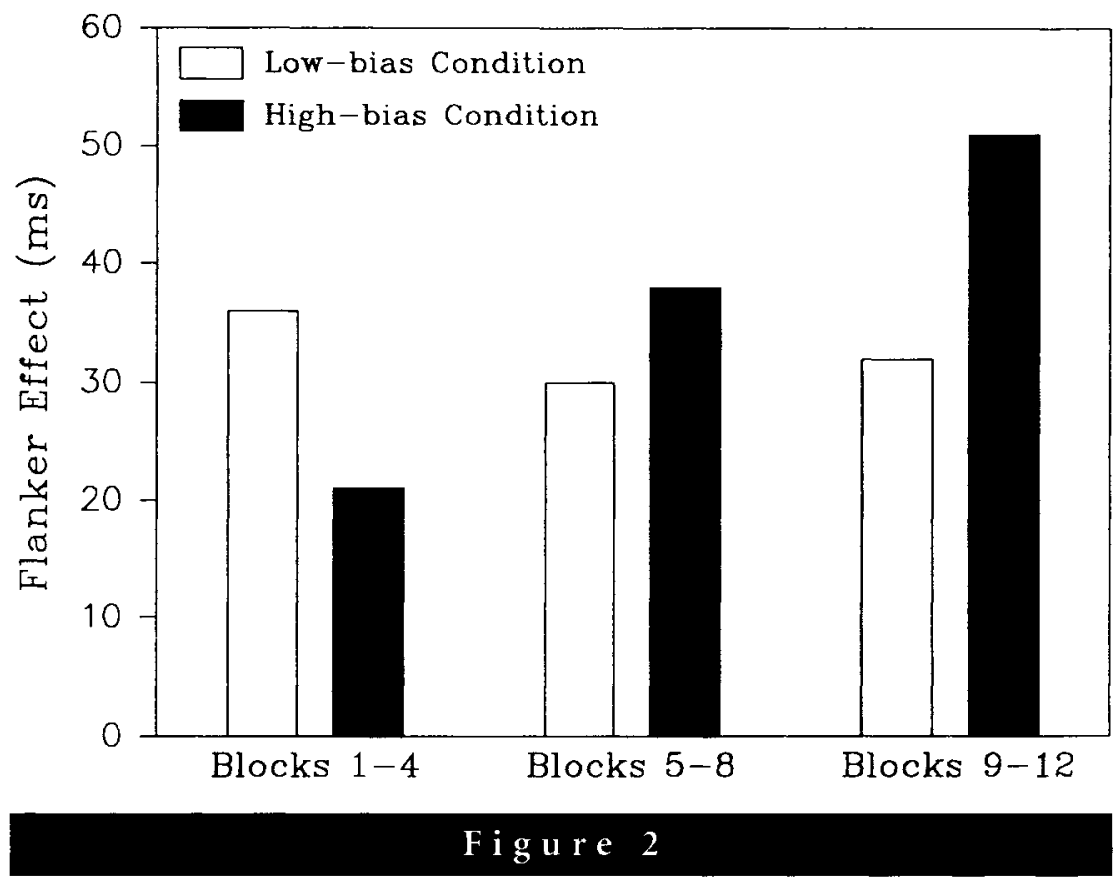

Mean flanker effects by session part and correlation strength; Experiment 1.

Error rates averaged about $5 \%$. An analysis of the errors provided no evidence of a speed-accuracy trade-off; conditions with large mean RTs also had high error rates. No effect in an analogous ANOVA to that concerning RT approached significance.

\section{Discussion}

The most important finding from this experiment was that increasing the contingency between the presence of a letter anywhere within the display and the correct response increases the observed flanker effect (but only after some experience with the task). Put another way: The magnitude of the flanker effect was found to covary with the value of typenode-response contingency bias (TRCB; Equation 4). This verifies the prediction of a contingency-based model of the flanker effect.

The finding that contingencies play an important role in determining selective-attention performance extends previous work demonstrating similar effects under divided attention (Mordkoff \& Egeth, 1994; Mord- 
koff \& Yantis, 1991). In fact, if one were to reanalyze the previous studies, one could easily show that non-target-response contingencies are functionally identical to typenode-response contingencies. This suggests that the contingency-sensitive mechanisms that are operative under dividedand selective-attention conditions are one and the same.

\section{STROOP COLOR AND WORD TEST AND VARIANTS}

The present form of contingency analysis can also be applied to other tasks requiring selective attention. For example, when subjects are asked to name the color of the ink in which a word is written, the semantic value of the word itself has a strong effect on how much time is required to produce the color-naming response. In particular, the time required to say "red" to a display of the word GREEN written in red ink is much greater than that required to say "red" to a display containing either the word $R E D$ in red ink or the letter-string $X X X X$ in red ink. This phenomenon is known as the Stroop effect (after Stroop, 1935).

The Stroop effect is open to an analysis in terms of typenode-response contingencies. Consider the experimental design given in Table 3, which is typical of Stroop color-naming tasks. Under the assumption that there exists a typenode for the concept red, which is activated by either red ink or the word $R E D$, one may refer to trials with matching ink color and word value as compatible in the same sense that was used for flankers-task trials with flankers that match the target. Similarly, trials with nonmatching ink color and word value are incompatible (e.g., the word GREEN in red

\section{Ta b le 3}

Trials per Block by Display Type for the Typical Stroop Color and Word Test

\begin{tabular}{|c|c|c|c|c|c|}
\hline \multirow{2}{*}{$\begin{array}{l}\text { Ink } \\
\text { color }\end{array}$} & \multirow{2}{*}{$\begin{array}{l}\text { Correct } \\
\text { response }\end{array}$} & \multicolumn{4}{|c|}{ Stimulus word } \\
\hline & & $R E D$ & GREEN & BLUE & YELLOW \\
\hline Red & “Red" & 3 & 1 & 1 & 1 \\
\hline Green & "Green" & 1 & 3 & 1 & 1 \\
\hline Blue & "Blue" & 1 & 1 & 3 & 1 \\
\hline Yellow & "Yellow" & 1 & 1 & 1 & 3 \\
\hline
\end{tabular}


ink). As for the flankers task, we may now calculate values of TRCB for the Stroop-task design given in Table 3:

$$
\begin{aligned}
& \mathrm{TRCB}=P\left(\mathrm{R} \text { red" }^{\prime} \mid \operatorname{red}^{@}\right)-P\left(\mathrm{R}{ }^{\text {red" }}\right) \\
& =P\left(\mathrm{R}_{\text {"green" }} \mid \text { green }^{\circledR}\right)-P\left(\mathrm{R}_{\text {"green" }}\right) \\
& =P\left(\text { R"blue" }^{\prime} \mid \text { blue }^{\circledR}\right)-P\left(\text { R"blue" }^{\prime}\right) \\
& =P\left(\mathrm{R}_{\text {"yellow" }} \mid \text { yellow }^{@}\right)-P\left(\mathrm{R}^{\text {"yellow" }}\right) \\
& =0.67-0.25=0.42
\end{aligned}
$$

where $P\left(\mathrm{R}\right.$ "red" $\mid$ red $\left.^{@}\right)$, for example, is the probability that "red" is the correct response given that red ink or the word $R E D$ (or both) are present in the display. The 0.67 results, for example, from the correct response being "red" for 6 out of the 9 trials (per block) that include either red ink or the word $R E D$ (or both). The 0.25 is the baseline probability that "red" is the correct response. The same holds for green, blue, and yellow. Thus, the value of TRCB for this Stroop task is $0.42 .{ }^{3}$

In summary, the design given in Table 3 , which is quite typical of published Stroop-task designs, includes a typenode-response contingency bias favoring compatible trials. Evidence of the effects of contingencies in a Stroop task has recently been obtained by Tzelgov, Henik, and Berger (1992), who manipulated the proportion of neutral trials in a manner very similar to the present Experiment 1. (The one difference is that these researchers manipulated the number of neutral trials between subjects.) An analysis of their designs and data revealed the predicted relationship between the proportion of neutral trials (and therefore the value of TRCB) and the observed magnitude of the Stroop effect (see Figure 3). Similar explanations in terms of typenode-response contingencies can also be advanced for the results of Stroop-task variants, such as the above-below task used by Logan and Zbrodoff (1979). Thus, the role that is played by

${ }^{3}$ It should be noted that the design shown in Table 3 also includes the equivalent of a flanker-target contigency bias in favor of compatible trials. In particular, the conditional probability that the color attribute is red is higher when the word is RED than when it is not. This bias also exists in most Stroop-task designs, but does not alter the present conclusion because it is not affected by manipulations of the number of neutral trials. 


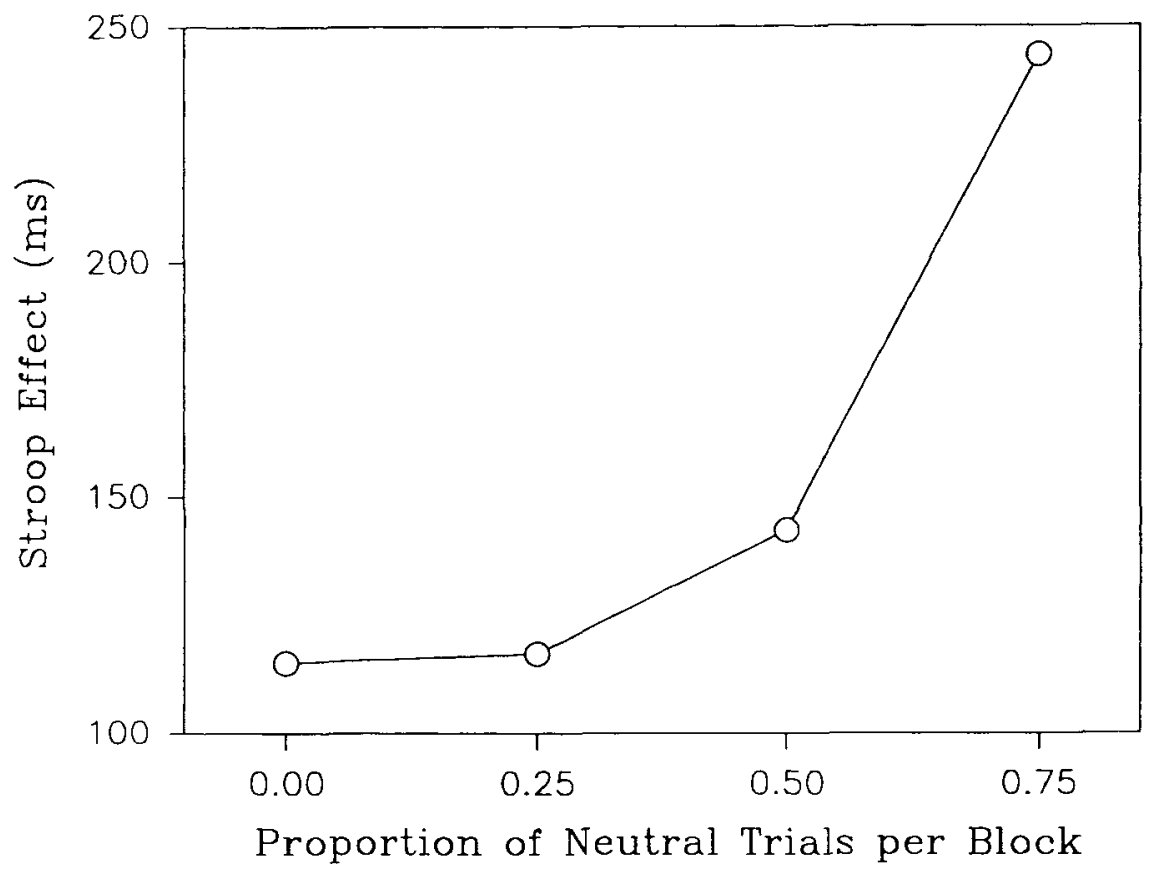

\section{Fig u re 3}

Mean magnitude of the Stroop effect plotted against the proportion of trials in the neutral condition. Data are from "Controlling Stroop Effects by Manipulating Expectations for Color Words," by J. Tzelgov, A. Henik, \& J. Berger, 1992, Memory and Cognition. Copyright 1992 by the Psychonomic Society. Adapted with permission.

contingencies in determining selective-attention performance may have wide generality.

\section{EXPERIMENT 2}

The preceding discussion raises the possibility that the flanker effect is entirely due to the operation of typenode-response contingencies. Such a conclusion would be very important because it would raise questions about the continuous flow of partial activations (C. W. Eriksen \& Schultz, 1979). This holds because the effects of typenode-response contingencies could occur after all perceptual processes have finished.

To test the idea that biased contingencies are completely responsible for the flanker effect, an experiment with zero TRCB is required. This, 
however, is not so simple a matter. As has been shown, adding neutral trials to an experimental design increases the contingency between typenode activation and the correct response. A design that includes no neutral trials has the lowest value of TRCB, but it is not zero. Therefore, in order to bring the value of TRCB to zero, an unbalanced design was used for Experiment 2.

\section{Method}

Experiment 2 was the same as Experiment 1 with two exceptions. First, the design was changed so that one set of targets ( $A$ and $Z$ in Table 4$)$ involved a zero value of TRCB. In particular, under this design,

$$
P\left(\mathrm{R}_{\mathrm{L}} \mid A^{@}\right)=P\left(\mathrm{R}_{\mathrm{L}} \mid Z^{@}\right)=P\left(\mathrm{R}_{\mathrm{L}}\right)
$$

and

$$
P\left(\mathrm{R}_{\mathrm{R}} \mid A^{@}\right)=P\left(\mathrm{R}_{\mathrm{R}} \mid Z^{@}\right)=P\left(\mathrm{R}_{\mathrm{L}}\right),
$$

so that the activation state of the $A$ and $Z$ typenodes provides no information concerning which response should be made. Only the data from the trials involving no TRCB were analyzed; these trials are marked with a superscript $a$ in Table 4. Note that these trials also include a small flankerresponse bias against compatible trials; this was unavoidable, but, as will

\section{Ta b l e 4}

Trials per Block by Display Type in Experiment 2

\begin{tabular}{lcccccr}
\hline \multirow{2}{*}{$\begin{array}{l}\text { Target } \\
\text { letter }\end{array}$} & $\begin{array}{c}\text { Correct } \\
\text { response }\end{array}$ & $A$ & $Z$ & $B$ & $Y$ & $N$ \\
\hline$A$ & $\mathrm{R}_{\mathrm{L}}$ & $6^{\mathrm{a}}$ & $6^{\mathrm{a}}$ & 0 & 0 & 0 \\
$Z$ & $\mathrm{R}_{\mathrm{R}}$ & $6^{\mathrm{a}}$ & $6^{\mathrm{a}}$ & 0 & 0 & 0 \\
$B$ & $\mathrm{R}_{\mathrm{L}}$ & 0 & 6 & 3 & 3 & 0 \\
$Y$ & $\mathrm{R}_{\mathrm{R}}$ & 6 & 0 & 3 & 3 & 0 \\
\hline
\end{tabular}

NOTE: $\mathrm{R}_{\mathrm{L}}=$ left-key response; $\mathrm{R}_{\mathrm{R}}=$ right-key response.

${ }^{a}$ Only these trials were analyzed. 
be seen, does not affect the conclusions. Second, in light of the results from Experiment 1, only the data from the final four blocks were analyzed. Twenty-four new subjects participated.

\section{Results and Discussion}

The condition without any biased typenode-response contingencies produced a small but reliable flanker effect of $26 \mathrm{~ms}, t(23)=2.11, p<.025$. Error rates again mirrored the RT data. Thus, it cannot be said that typenode-response contingencies are the sole cause of the flanker effect. That a significant flanker effect was observed when flanker-response contingencies were biased against compatible trials only increases the argument against a contingency-based explanation of the flanker effect.

As it turns out, there are several other problems with a contingencybased model of the flanker effect. Three examples of this are (a) unreported experiments have shown that the effect of contingencies in letterdetection tasks is case specific (see also Miller \& Hardzinski, 1981), which contradicts any links between the present analysis and typenode systems (see Kanwisher, 1987); (b) other designs that include differing levels of TRCB (but unequal target frequencies) do not always reveal different-size flanker effects; and (c) the model predicts an advantage for compatible trials with same-response flankers (e.g., $B A B$ ) over those with identical flankers (e.g., $A A A$ ), which does not obtain (see, e.g., B. A. Eriksen \& Eriksen, 1974). However, the effects observed in Experiment 1 have been replicated several times using various designs, so the influence of contingencies on selective attention must still be considered. If nothing else, it serves as an alternative interpretation of the effects of increasing the number of neutral trials (Tzelgov et al., 1992) or varying the proportion of compatible trials (Logan \& Zbrodoff, 1979).

\section{SUMMARY}

This study examined selective-attention performance from the perspective of someone who is particularly fond of internal constraints (Garner, 1962). It was first shown that biased contingencies have been included in nearly all published demonstrations of the flanker effect (e.g., B. A. Eriksen \& Eriksen, 1974). The results from Experiment 1 then showed that when these contingencies are manipulated, the magnitude of the flanker 
effect is altered as well. Similar manipulations of the contingencies in other selective-attention tasks have revealed the same pattern (e.g., Tzelgov et al., 1992). Thus, preliminary results suggest that the flanker effect of selective attention-like certain effects of divided attention (see Mordkoff \& Yantis, 1991)-may be entirely due to internal constraints.

This argument was then tested in a second experiment. Here it was found that when the crucial contingency is set to zero (and other contingencies are zero or biased against the effect), a significant flanker effect is still observed. Thus, although it has here been shown again that internal constraints can alter performance, there is more to the flanker effect than biased contingencies.

\section{REFERENCES}

Coles, M. G. H., Gratton, G., Bashore, T. R., Eriksen, C. W., \& Donchin, E. (1985).

A psychophysiological investigation of the continuous flow model of human information processing. Journal of Experimental Psychology: Human Perception and Performance, 11, 529-553.

Eriksen, B. A., \& Eriksen, C. W. (1974). Effects of noise letters upon the identification of a target letter in a nonsearch task. Perception and Psychophysics, 16, 143-149.

Eriksen, C. W., \& Hoffman, J. E. (1972). Temporal and spatial characteristics of selective attention. Perception and Psychophysics, 12, 201-204

Eriksen, C. W., \& Hoffman, J. E. (1973). The extent of processing of noise elements during selective encoding from visual displays. Perception and Psychophysics, 14, 155-160.

Eriksen, C. W., \& Schultz, D. W. (1979). Information processing in visual search: A continuous flow conception and experimental results. Perception and Psychophysics, 25, 249-263.

Eriksen, C. W., \& St. James, J. D. (1986). Visual attention within and around the field of focal attention: A zoom lens model. Perception and Psychophysics, 40, 225-240.

Eriksen, C. W., \& Yeh, Y.-Y. (1985). Allocation of attention in the visual field. Journal of Experimental Psychology: Human Perception and Performance, 11, 583-597.

Garner, W. R. (1962). Uncertainty and structure as psychological concepts. New York: Wiley.

Gratton, G., Coles, M. G. H., Sirevaag, E. J., Eriksen, C. W., \& Donchin, E. (1988). Pre- and post-stimulus activation of response channels: A psychophysiological 
analysis. Journal of Experimental Psychology: Human Perception and Performance, 14, 331-344.

Kanwisher, N. G. (1987). Repetition blindness: Type recognition without token individuation. Cognition, 27, 117-143.

Kanwisher, N. G. (1991). Repetition blindness and illusory conjunctions: Errors in binding visual types with visual tokens. Journal of Experimental Psychology: Human Perception and Performance, 17, 404-421.

Logan, G. D., \& Zbrodoff, N. J. (1979). When it helps to be misled: Facilitative effects of increasing the frequency of conflicting stimuli in a Stroop-like task. Memory and Cognition, 7, 166-174.

Miller, J. (1987). Priming is not necessary for selective-attention failures: Semantic effects of unattended, unprimed letters. Perception and Psychophysics, 41, 419-434.

Miller, J., \& Hardzinski, M. (1981). Case specificity of the stimulus probability effect. Memory and Cognition, 9, 205-216.

Mordkoff, J. T., \& Egeth, H. E. (1994). Response time and accuracy revisited: Converging support for the interactive race model. Journal of Experimental Psychology: Human Perception and Performance, 19, 981-991.

Mordkoff, J. T., \& Yantis, S. (1991). An interactive race model of divided attention. Journal of Experimental Psychology: Human Perception and Performance, 17, $520-538$.

Morton, J. (1969). Interaction of information in word recognition. Psychological Review, 76, 165-178.

Mozer, M. C. (1989). Types and tokens in visual letter perception. Journal of Experimental Psychology: Human Perception and Performance, 15, 287-303.

Paquet, L., \& Lortie, C. (1990). Evidence for early selection: Precuing target location reduces interference from same-category distractors. Perception and Psychophysics, 48, 382-388

Stroop, J. (1935). Studies of interference in serial verbal reaction. Journal of Experimental Psychology, 18, 643-662.

Treisman, A. M. (1988). Features and objects: The Fourteenth Bartlett Memorial Lecture. Quarterly Journal of Experimental Psychology, 40A, 201-237.

Tzelgov, J., Henik, A., \& Berger, J. (1992). Controlling Stroop effects by manipulating expectations for color words. Memory and Cognition, 20, 727-735. 